
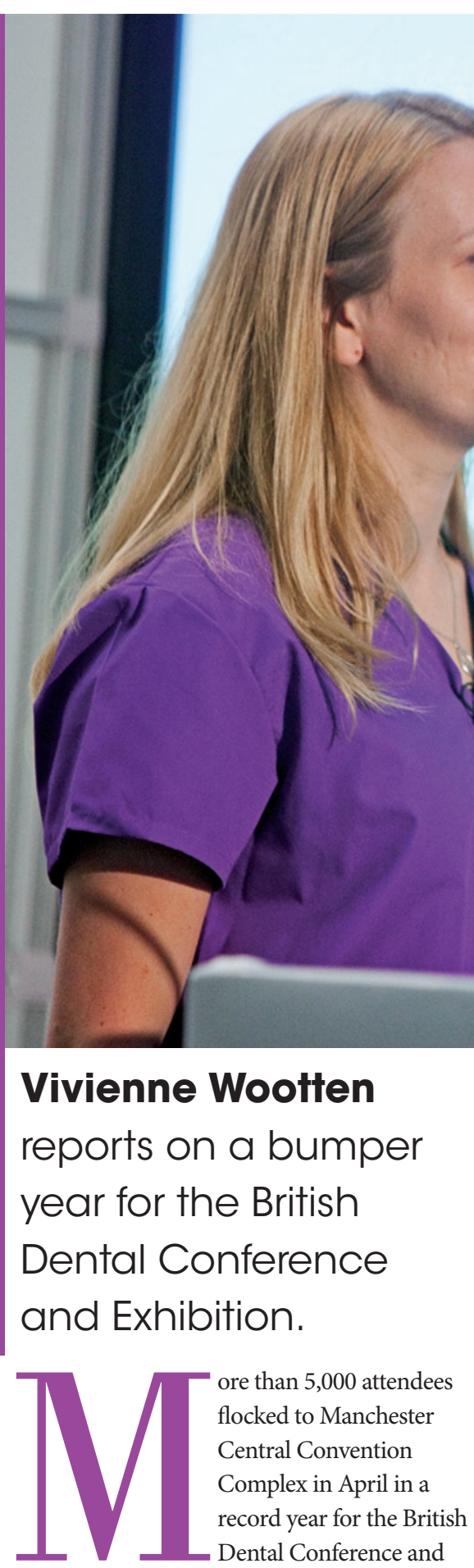

Exhibition. They were treated to an exciting variety of seminars, demonstrations, lectures and social events, and even had the chance to meet Marilyn Monroe.

\section{Speakers look to the future}

Topping the bill were the event's keynote speakers Professor Susan Greenfield and Minister for Health, Earl Howe. Speaking to a packed Exchange Auditorium of 1,600 on Thursday, eminent brain scientist Professor Greenfield provided a fascinating insight into how the brain develops and how we become who we are. She suggested that the increasing popularity of computer games and social media
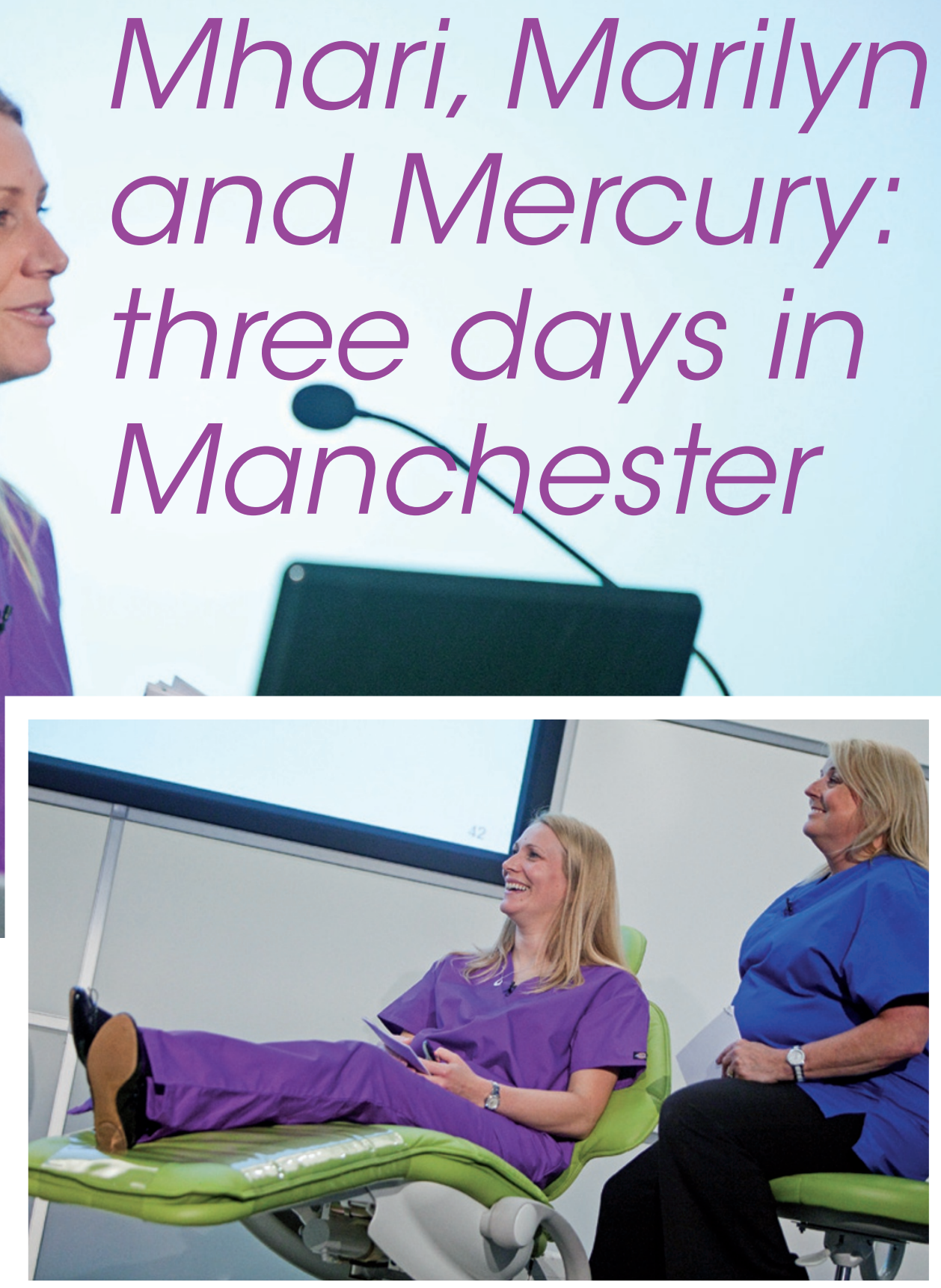

may actually be affecting the way our brains develop, leading to a decline in social skills and a need for instant stimulation.

The following morning Earl Howe, the Minister responsible for NHS dentistry in England, took to the stage. His message to delegates was that, although he believed good progress had been made on dentistry in the last 12 months, challenges remained and there was still a great deal to be learnt in the process of developing a new dental contract. The changes to the way that dentistry is commissioned in England were also at the front of the Minister's mind. The changes will, he assured delegates, mean greater consistency in the way care is commissioned.

The pilots for a new contract were also the theme of a debate session on the same day.
The session considered several aspects of the potential effect of new arrangements, including the evolving nature of the dental workforce, both in terms of the role of associate dentists and that of dental care professionals (DCPs).

\section{Working together}

The importance of the dental team working together was a common theme across many sessions. A seminar on the importance of communication in practice saw delegates learning through laughter as they watched a team of dental professionals presenting a series of mini role-plays illustrating common communication mistakes. Hygienist Mhari Coxon made an impression playing the aggressive hygienist who bullied her patients and criticised her colleagues. 
A presentation on the team approach to tooth whitening showed how offering tooth whitening can help bind the team together, with everyone promoting the service and receiving the relevant training to carry out tasks such as making bleaching trays and pouring models. Even CQC inspections provided positive team building opportunities, explained Sue Boynton from Dental Protection. Working together to prepare for inspections and using positive feedback from the inspections to promote the practice could provide a useful boost to practice morale.

\section{Important lessons}

For those looking to provide a quality dental service and continuity of care to their patients, keeping complete and retrievable dental records was key, stressed Rupert Hoppenbrouwers, Head of the Dental Defence Union. He emphasised how a well-handled complaint can lead to one fewer cases going before the dental regulator.

The issue of how to protect vulnerable children was tackled by Jenny Harris, Consultant in Community Paediatric Dentistry. She looked at the importance of sharing information and recommended useful guidance such as the Department of Health's Child protection in the dental team. Detection and referral was also a key feature of oral and maxillofacial surgeon Steve Laughton's seminar on oral cancer where he highlighted how lives can be saved through early detection of the condition and prevention advice from the team.

\section{A packed exhibition hall}

One of the most exciting features at the event was the new demonstration theatre in the Exhibition hall. With every seat taken and people standing outside, the theatre proved extremely popular with presentations on clinical dentistry, dealing with patients and practice work. Using a mock-up of a real-life dental surgery, complete with phantom head simulators, a wide variety of demonstrations took place, including the live sedation of a volunteer.

As well as the live demonstration theatre the Exhibition hall also featured the Training essentials theatre where delegates queued up to top up their CPD with a series of bite-sized lectures covering topics such as inspection, marketing, medical emergencies and motivating patients to improve their oral health.

However, the two theatres were just a small element of what was on offer in the Exhibition hall. It was a constantly moving and changing place where Marilyn Monroe and a giant walking tooth could occasionally be seen amongst the crowds and where the scent of popcorn could be detected around the stand of one particular exhibitor. Another exhibitor

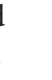

reported on Twitter that they sold out of one of their products over the course of the event and the British Dental Association received positive feedback on the new online booking system for meeting with exhibitors.

\section{Getting together}

During the day delegates could take a break to chat and network at one of the many catering and conversation points, as well as resting their tired feet (further relaxation was provided at the massage areas!). In the evening plenty of fun and conversation and further opportunities to mingle with colleagues were on offer. On Thursday night delegates gathered for evening drinks in the Exhibition hall giving them the

\section{'A SEMINAR ON THE IMPORTANCE OF} COMMUNICATION IN PRACTICE SAW DELEGATES

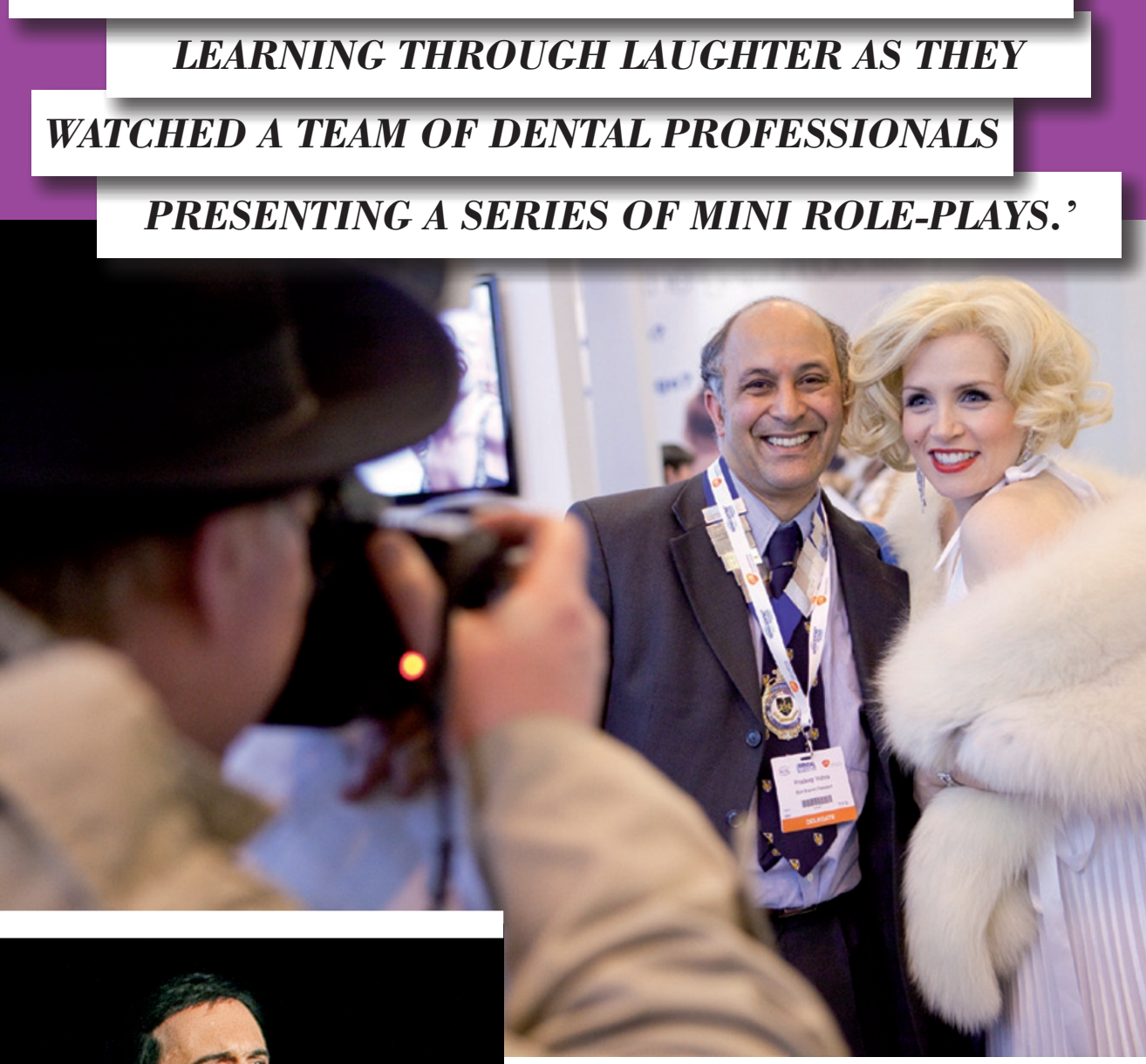

